\title{
REVIEW
}

\section{Hormonal contraception in women with the metabolic syndrome: A narrative review}

\author{
Johan Verhaeghe \\ Department of Obstetrics and Gynaecology, University Hospital Gasthuisberg, Katholieke Universiteit Leuven, \\ Leuven, Belgium
}

A B S T R A C T

Objective The metabolic syndrome (MS) is a set of five cardiovascular and metabolic risk factors: elevated waist circumference, fasting plasma glucose, triglycerides and blood pressure; and reduced HDL-cholesterol. The prevalence of the MS is rising worldwide, and is linked to two diagnoses in young women: polycystic ovary syndrome (PCOS) and gestational diabetes mellitus (GDM).

Methods This narrative review focuses on hormonal contraceptive choices available for women in Europe with features of the MS.

Results The levonorgestrel-intrauterine system and progestogen-only pills containing desogestrel or levonorgestrel have no significant effects on MS parameters. Combined oestrogen-progestogen methods do not appear to increase waist circumference or the incidence of glucose intolerance in women with PCOS or a history of GDM; their effect on HDL-cholesterol and triglycerides is comparable with that observed in women without the MS, while the effect on blood pressure remains inconclusive. The etonogestrel implant does not affect body weight, triglycerides and blood pressure but mildly reduces insulin sensitivity and HDL-cholesterol in healthy women. Depot medroxyprogesterone acetate increases body weight and truncal fat deposition, and lowers glucose tolerance in women with previous GDM.

Conclusions Low-dose hormonal contraception is safe for many women with the MS, but high-dose progestogens must be avoided.

K E Y W O R D S Blood pressure; Gestational diabetes mellitus; HDL-cholesterol; Insulin resistance; Obesity; Polycystic ovary syndrome; Triglycerides; Waist circumference

Correspondence: Johan Verhaeghe, MD, PhD, Department of Obstetrics and Gynaecology, Katholieke Universiteit Leuven, Health Sciences Campus Gasthuisberg, Herestraat 49, 3000 Leuven, Belgium. Tel: +32 16344212. Fax: +32 16344205; E-mail: johan.verhaeghe@uz.kuleuven.be 
THE METABOLIC SYNDROME IN W O MEN

The metabolic syndrome (MS) is not a single-cause multiple-trait disease, but a cluster of characteristics indicative of increased cardiovascular and metabolic risk. Reaven was the first to elaborate on several clinical and biochemical signs apparently related to insulin resistance ${ }^{1}$. His insights triggered an avalanche of studies examining a 'syndromatic' construct of metabolic risk factors, which by gradual consensus became known as the MS. Several diabetes and cardiovascular expert panels and societies have proposed overlapping criteria for the MS between 1999 and 2005, yet a consensus is slowly emerging. The latest set of criteria, a joint effort of several international organisations $^{2}$, is summarised in Table 1. The optimal threshold for central fat accumulation, as estimated by the waist circumference, is uncertain and ethnicityspecific cut-off points have been proposed ${ }^{2}$.

Despite growing consensus on the five criteria, the MS remains a highly controversial entity. A recent WHO expert report concludes that the MS is useful as an educational concept but not as a clinical tool ${ }^{3}$. Many, including Reaven himself, have called for its immediate demise ${ }^{4}$. The author disagrees. There is no doubt that the MS offers little or no extra value to clinicians caring for patients with established type 2 diabetes or coronary heart disease. However, the MS is a premorbid condition ${ }^{3}$, an 'anteroom' for possible future metabolic and cardiovascular derangement. Surely, practitioners caring for young women should

Table 1 Criteria for the clinical diagnosis of the metabolic syndrome (MS) in women*

\begin{tabular}{|c|c|}
\hline Measure & Categorical cut-off points \\
\hline levated waist circumference & $\geq 80$ or $88 \mathrm{~cm}^{* *}$ \\
\hline Elevated triglycerides*** & $\geq 150 \mathrm{mg} / \mathrm{dl}(1.7 \mathrm{mmol} / \mathrm{l})$ \\
\hline Reduced HDL-cholesterol*** & $<50 \mathrm{mg} / \mathrm{dl}(1.3 \mathrm{mmol} / \mathrm{l})$ \\
\hline Elevated blood pressure ${ }^{* * *}$ & $\begin{array}{l}\text { Systolic } \geq 130 \text { and/or } \\
\quad \text { diastolic } \geq 85 \mathrm{~mm} \mathrm{Hg}\end{array}$ \\
\hline Elevated fasting glucose ${ }^{* *}$ & $\geq 100 \mathrm{mg} / \mathrm{dl}(5.6 \mathrm{mmol} / \mathrm{l})$ \\
\hline
\end{tabular}

*Three or more abnormal results are necessary for a diagnosis of the MS.

**The optimal waist circumference cut-off remains uncertain and may be ethnicity-specific.

***Drug treatment aimed at reversing this particular condition is an alternate indicator. do their utmost to advise them on how they might avoid being led into the 'clinical room'. The presence of one metabolic risk factor should prompt a thorough evaluation of other risk factors. Disappointingly, this is not yet embedded in current clinical practice. Based upon the individual metabolic signature, caregivers should discuss lifestyle choices and address specific issues such as contraception.

Two clinical entities in women of reproductive age are highly associated with the MS: the polycystic ovary syndrome (PCOS) and gestational diabetes mellitus (GDM). The prevalence of the MS is around $40 \%$ in American women with a diagnosis of $\mathrm{PCOS}^{5}$, at least in those who present with hyperandrogenism ${ }^{6}$; in Europe, the prevalence may be somewhat lower ${ }^{5}$. Women with PCOS are at higher risk for glucose intolerance and type 2 diabetes $^{7}$ and probably cardiovascular disease as well ${ }^{5}$. The prevalence of the MS was threefold higher in Danish women with a history of diettreated GDM than in age-matched controls ${ }^{8}$; including insulin-treated GDM would result in an even higher risk. After adjustment for body mass index (BMI), an elevated pre-pregnancy waist circumference remained a risk factor for GDM in a large USA cohort ${ }^{9}$. Thus, central adipose tissue accumulation in young women is a portent of metabolic and cardiovascular pathology.

The prevalence of GDM around the globe has increased in recent decades ${ }^{10}$. The same may be true for PCOS: for example, a recent Australian study produced a prevalence estimate of more than $10 \%$ among young women ${ }^{11}$. The rising tide of both obesity and the MS is, at least in part, responsible for this development. The present narrative review examines the contraceptive options for women with features of the MS, PCOS or a history of GDM. A literature search was performed using the author's dedicated library, amplified by reference hand search. References were selected on the basis of perceived scientific relevance and a focus on hormonal contraceptive methods currently available in Europe. Clearly, none of the non-hormonal contraceptive methods has any effect on cardiovascular and metabolic risk.

C O N T R A C E P T I VE CHOICES FOR W OMEN WITH CENTRAL A DIPOSE A C C UMULA T I O N

The only method with a deleterious effect on body weight and fat distribution is the depot 
medroxyprogesterone acetate (DMPA) injection (150 mg i.m.). In a prospective study, 30 months of DMPA use was accompanied by increases in both body weight and fat mass of $6.1 \mathrm{~kg}$ on average, and a linear increment over time in the ratio of central (trunk) over peripheral (limbs) fat ${ }^{12}$. Women with a central adipose distribution at baseline showed a greater DMPAinduced trunk fat accumulation ${ }^{12}$. Visceral adiposity aggravates insulin resistance in the liver through the release and portal vein efflux of free fatty acids and other adipose tissue secretory products (adipokines) ${ }^{13}$. Weight gain was observed in the majority of SouthAfrican overweight/obese adolescents on $\mathrm{DMPA}^{14}$. In addition, a 3.6-fold higher weight gain rate was documented in a cohort of generally overweight postpartum Hispanic-American women with a history of GDM who used DMPA compared with those resorting to non-hormonal contraception ${ }^{15}$. Weight gain also occurred with the lower-dosed DMPA $104 \mathrm{mg}$ administered subcutaneously ${ }^{16}$. Several mechanisms may explain the DMPA-induced weight gain, including increased appetite ${ }^{12}$.

The effect of the single-rod etonogestrel implant on body weight is uncertain, but a sustained weight increment of more than $2 \mathrm{~kg}$ in comparison with untreated women can probably be excluded ${ }^{17}$. Progestogen-only pills (POPs) containing either desogestrel $0.075 \mathrm{mg}$ or levonorgestrel $0.03 \mathrm{mg}$, do not appear to influence body weight ${ }^{18}$.

Regarding combined oral contraceptives (COCs), a meta-analysis concluded that the available evidence on weight change is insufficient; while some studies reported a weight gain of up to $1.8 \mathrm{~kg}$ after 12 cycles, a large effect can be excluded ${ }^{19}$. Small increases in fat mass or body water $(<1 \mathrm{~kg})$ were documented after six cycles in some studies ${ }^{20,21}$ but again, the changes appear clinically insignificant for COCs, the combination patch and the vaginal ring. In overweight or obese women with PCOS (mean baseline BMI $29.2-37.8 \mathrm{~kg} / \mathrm{m}^{2}$ ), COCs did not influence BMI or waist circumference after six cycles $^{22-25}$. In the study of women with previous GDM already mentioned, weight gain rate among COC users was comparable to that among nonhormonal contraception users ${ }^{15}$.

Obesity affects the pharmacokinetics of drugs, leading to a doubling of the interval needed to reach steady-state levels of some COC compounds ${ }^{26}$. Hence, there is a greater likelihood for 'escape' FSH and LH pulsatile activity, follicle growth and ovulation in obese users of $\mathrm{COCs}^{26}$ or a combination vaginal ring $^{27}$. It remains unclear whether obese women using combination methods are at higher risk for method failure $^{28}$ but one clinical trial reported a greater than expected incidence of pregnancies with the combined patch in women whose weight exceeded $90 \mathrm{~kg}^{29}$. A shortened pill-free interval (four days instead of the conventional seven) ameliorated ovarian suppres$\operatorname{sion}^{30}$, and might be particularly helpful in obese women. When starting hormonal contraceptives, obese women should use back-up contraception in the first $7-10$ days (10 days being the mean interval needed to reach progestogen steady-state concentrations ${ }^{26}$ ).

There is no consensus at present with regard to whether the risk of venous thromboembolism in COC users is BMI-dependent, since five studies examining this issue have produced inconsistent results ${ }^{31}$. Until more data become available, obese women should remain eligible for combination methods, regardless of their BMI or fat distribution (WHO category 2$)^{31}$.

\section{CONTRACEPTIVE CHOICES FOR W OMEN WITH GLYCAEMIC A B N O R M A L I T I E S}

Progesterone and progestogens reduce tissue insulin sensitivity, thereby leading to a compensatory increase in insulin release following a glucose load. The magnitude of the effect is dose-dependent and may be compound-specific ${ }^{32,33}$. In women with the MS, the combination of baseline insulin resistance and progestogen use might accelerate the development of impaired glucose tolerance/postprandial hyperglycae$\mathrm{mia}^{34}$. There is no evidence that ethinylestradiol worsens insulin sensitivity ${ }^{35}$; in fact, oestrogen therapy appears to improve insulin sensitivity in oestrogendeficient individuals ${ }^{36,37}$.

Table 2 summarises the methodology to evaluate glucose metabolism in humans. The most frequently used methods by far are fasting blood samples and the oral glucose tolerance test (OGTT), from which numerous insulin sensitivity and secretion indices have been derived. Although several of these indices have been reasonably well validated against the hyperinsulinaemic euglycaemic clamp, the 


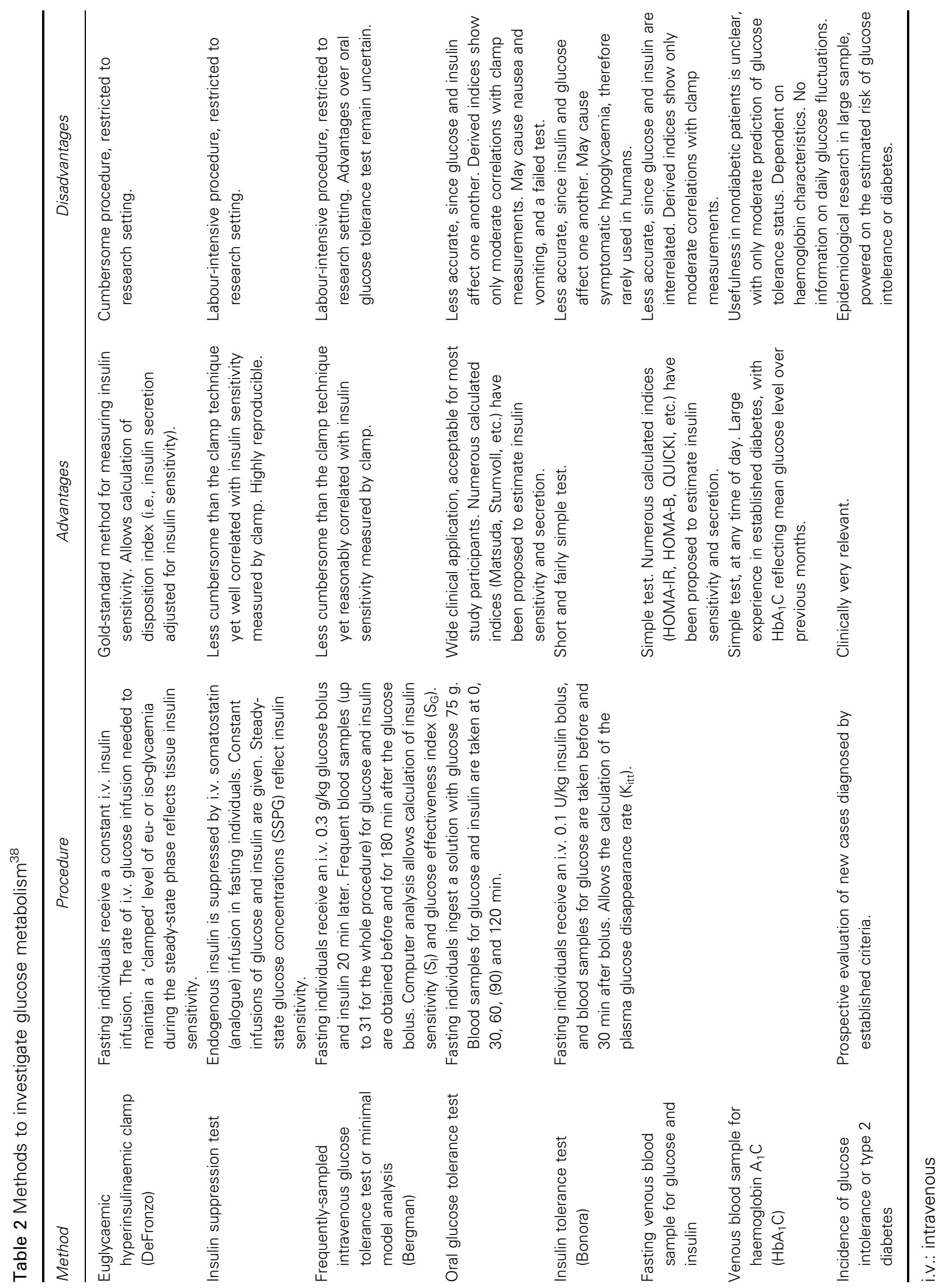


gold-standard method, their limitations should be kept in $\operatorname{mind}^{38}$.

Use of DMPA in postpartum women with previous GDM was associated with an early (within one to two years) rise in the incidence of type 2 diabetes, compared with COC use; the risk was about fourfold higher in women with baseline triglycerides $>150 \mathrm{mg} / \mathrm{dl}^{39}$. These findings were replicated in another USA cohort ${ }^{40}$.

Lower-dose progestogen-only methods have milder or no effects. Although the etonogestrel implant reduced insulin sensitivity by about 30\% in healthy women, as measured by the frequently-sampled intravenous (i.v.) glucose tolerance test ${ }^{41}$, preliminary data in diabetic women indicated no change in $\mathrm{HbA}_{1} \mathrm{C}$ levels within two years of $\mathrm{use}^{42}$. POPs containing desogestrel or levonorgestrel had no meaningful effect on OGTT parameters and $\mathrm{HbA}_{1} \mathrm{C}$ levels in healthy women ${ }^{43}$. Compared with copper intrauterine devices, the levonorgestrel-intrauterine system (LNG-IUS) did not affect fasting glucose or $\mathrm{HbA}_{1} \mathrm{C}$ levels over a one-year period in women with type 1 diabetes ${ }^{44}$.

Low-dose COCs variably affected insulin sensitivity in healthy women ${ }^{45}$, while the vaginal ring showed minimal or no effect on insulin sensitivity ${ }^{46,47}$. A meta-analysis of clinical trials with OGTT data concluded that COCs as a class have no consistent and relevant effect on glucose metabolism in women without diabetes ${ }^{48}$. In addition, there was no evidence of a meaningful difference between the available lowdose COC preparations ${ }^{48}$.

In women with PCOS, the reported effects of COCs during 3-12 cycles are largely reassuring, showing no effect on insulin sensitivity assessed by the euglycaemic clamp ${ }^{22,49,50}$, frequently-sampled i.v. glucose tolerance test ${ }^{51}$, OGTT ${ }^{24,52}$, insulin tolerance test $^{53}$, or a fasting blood sample $\mathrm{e}^{54,55}$, independent of baseline BMI. Neither was there an effect on the incidence of glucose intolerance ${ }^{24}$. However, in some studies, a slight deterioration in insulin sensitivity was observed with at least one COC preparation ${ }^{51,56,57}$. In comparative trials examining the impact of two COCs, the lower-dose preparation had more favourable effects $^{23,56}$.

Use of COCs in women with a history of GDM did not appear to accelerate the recurrence of glucose intolerance or diabetes ${ }^{15,39}$.

\section{CONTRACEPTIVE CHOICES FOR W OMEN W I T H}

HY PER TRIGLYCERIDAEMIA OR

L O W HDL-CHOLES TEROL

The generally held view is that ethinylestradiol increases triglyceride levels dose-dependently, whereas the progestogen may reduce HDL-cholesterol depending on dose and androgenic properties. The impact of these changes on the development of atherosclerosis remains unknown.

A rise in plasma triglycerides has been observed consistently in healthy women using low-dose $\mathrm{COCs}^{58-60}$, the patch $^{61}$ and the ring ${ }^{62}$. The magnitude of change varied considerably between studies but was within the twofold range; the ring produced a slightly higher increase than a levonorgestrel-containing COC in one study ${ }^{62}$. In overweight/obese women with PCOS, either no significant change in triglycerides ${ }^{24,25,54,55}$ or an increment within the twofold range ${ }^{53,63}$ was documented during $\mathrm{COC}$ use; in women with a history of GDM, there was no COC-induced change in plasma triglycerides ${ }^{64,65}$. The data show that there is no amplified triglyceride response to COCs in women with PCOS or previous GDM; in fact, the response may be attenuated in those with higher baseline levels ${ }^{64,65}$. Progestogen-only methods, namely, the LNG-IUS ${ }^{66}$, the etonogestrel implant $^{67,68}$, and desogestrel- or levonorgestrelcontaining $\mathrm{POPs}^{69}$, do not raise plasma triglycerides.

The changes in HDL-cholesterol induced by hormonal contraceptives are small. The etonogestrel implant and levonorgestrel-containing COCs caused a 10$20 \%$ reduction in HDL-cholesterol in healthy women ${ }^{62,67,68}$. On the other hand, the LNG-IUS ${ }^{66}$, desogestrel- or levonorgestrel-containing $\mathrm{POPs}^{69}$, the combined patch ${ }^{61}$ and ring ${ }^{62}$, and COCs containing desogestrel $^{58}$ or drospirenone ${ }^{60}$ were associated with stable or up to $20 \%$ increased levels. In women with PCOS, increased HDL-cholesterol levels during COC use were reported consistently ${ }^{24,25,50,52-55,57,63}$. In women with a history of GDM, the HDL-cholesterol levels were also higher in COC users than in those using non-hormonal methods ${ }^{15}$.

In sum, there is no evidence that hormonal contraceptives have a more deleterious effect on triglycerides and HDL-cholesterol levels in women 
with PCOS or a history of GDM than in healthy women.

\section{CONTRACEPTIVE CHOICES FOR W OMEN WITH HYPERTENSION}

Low-dose COCs produced a very small $(<1 \mathrm{~mm} \mathrm{Hg})$ and reversible increase in mean systolic and diastolic blood pressure in unselected populations. In a large USA cohort, COC use doubled the relative risk of a diagnosis of hypertension within four years, corresponding to four diagnoses per 1,000 woman-years attributable to $\mathrm{OC} \mathrm{use}^{70}$. Thus, the overwhelming majority of normotensive women who take COCs remain normotensive.

In women with established hypertension, two studies reported a further increase in blood pressure, but the available evidence was deemed of low quality ${ }^{71}$. Hypertension and COC use may also act synergistically to increase the risk of myocardial infarction and stroke but, again, the evidence is inconclusive, and the estimated incidence of cardiovascular events is low even in hypertensive women who take COCs (three events per 10,000 woman-years between 20-40 years of age $)^{71}$. Drospirenone is a progestogen with antimineralocorticoid and therefore mildly antihypertensive properties $^{72} \quad(1 \mathrm{mg}$ drospirenone $\approx 8 \mathrm{mg}$ spironolactone). A small trial showed a slight drop in blood pressure $(1-4 \mathrm{~mm} \mathrm{Hg})$ with drospirenonecontaining $\mathrm{COCs}^{73}$. There is a pressing need for clinical trials that examine the blood pressure effects of different COC preparations in healthy women and in women with PCOS, previous GDM, or the MS. Until more data become available, a diagnosis of severe hypertension based upon correct and repeated measurements (systolic $>160$ and diastolic $>100 \mathrm{~mm}$ $\mathrm{Hg}$ ), is a contraindication (WHO category 4) for any combined COC, patch or ring; mild hypertension (systolic 140-159 and diastolic $90-99 \mathrm{~mm} \mathrm{Hg}$ ) is a relative contraindication (WHO category 3$)^{74}$.

The etonogestrel implant ${ }^{75}$ and POPs available in Europe $^{18}$ did not affect blood pressure in healthy users. Neither did DMPA influence blood pressure in women with a history of $\mathrm{GDM}^{15}$.

\section{G E N E R A L R E C O M M E N D A T I O N S}

Features of the MS are common in adolescent and adult women in 2010. There are no studies on the effect of hormonal contraceptives in women with predefined MS. Yet a fair amount of data is available from two populations with a considerably higher prevalence of MS, namely, women with either PCOS or a history of GDM.

Oestrogens and progestogens have the biological potential to influence body weight and fat distribution, insulin sensitivity and glucose tolerance, plasma lipids, and blood pressure. Non-hormonal methods should therefore remain the first-line contraceptive choice in women with features of the MS. However, the LNGIUS and low-dose POPs have no meaningful metabolic and blood pressure effects. Hence, clinicians and women contemplating either one of these methods on the basis of sound judgement, should not be denied this choice because of the presence of features of the MS.

But low-dose combined methods are not necessarily contra-indicated in metabolically-challenged women. With COCs or the vaginal ring, there is no solid evidence of a heightened risk of central fat accumulation, glucose intolerance or lipid profile deterioration in women with PCOS or a history of GDM. Nonetheless, women with baseline hypertriglyceridaemia should be observed closely for deterioration of glucose tolerance and the lipid profile. In addition, currently accepted contra-indications including hypertension should be taken into account. To improve the efficacy of low-dose combined methods, a short or no hormone-free interval may be preferable, but more data are needed in this regard. Back-up condom use (the 'double Dutch') may also be recommended.

The jury is still out on the overall metabolic impact of the etonogestrel implant: more studies are needed with regard to the effects this contraceptive may have on glucose tolerance and HDL-cholesterol in women with features of the MS. But DMPA use should be discouraged in women with the MS, because of its deleterious effects on weight gain, fat distribution and glucose tolerance. Systematic reviews are mandatory to corroborate the present recommendations based on the author's overview of the literature.

Declaration of interest: The author reports participating in expert meetings organised by Bayer Schering and Merck Serono, and receiving honoraria for consultancy and lectures from Bayer Schering, Merck Serono and Schering Plough. The author alone is responsible for the content and the writing of the paper. 
R E F E R E N C E S

1. Reaven GM. Banting Lecture 1988. Role of insulin resistance in human disease. Diabetes 1988;37:1595-607.

2. Alberti KGMM, Eckel RH, Grundy SM, et al. Harmonizing the metabolic syndrome: A joint interim statement of the International Diabetes Federation task force on epidemiology and prevention; National Heart, Lung, and Blood Institute; American Heart Association; World Heart Federation; International Atherosclerosis Society; and International Association for the Study of Obesity. Circulation 2009;120:1640-5.

3. Simmons RK, Alberti KGMM, Gale EAM, et al. The metabolic syndrome: Useful concept or clinical tool? Report of a WHO expert consultation. Diabetologia 2010;53:600-5.

4. Reaven GM. The metabolic syndrome: Requiescat in pace. Clin Chem 2005;51:931-8.

5. Wild RA, Carmina E, Diamanti-Kandarakis E, et al. Assessment of cardiovascular risk and prevention of cardiovascular disease in women with the polycystic ovary syndrome: A consensus statement by the Androgen Excess and Polycystic Ovary Syndrome (AE-PCOS) Society. J Clin Endocrinol Metab 2010;95:2038-49.

6. Shroff R, Syrop CH, Davis W, et al. Risk of metabolic complications in the new PCOS phenotypes based on the Rotterdam criteria. Fertil Steril 2007;88:1389-95.

7. Tomlinson J, Millward A, Stenhouse E, et al. Type 2 diabetes and cardiovascular disease in polycystic ovary syndrome: What are the risks and can they be reduced? Diabetic Med 2010;27:498-515.

8. Lauenborg J, Mathiesen E, Hansen $\mathrm{T}$, et al. The prevalence of the metabolic syndrome in a Danish population of women with previous gestational diabetes mellitus is three-fold higher than in the general population. J Clin Endocrinol Metab 2005;90:4004-10.

9. Yeung EH, Hu FB, Solomon CG, et al. Life-course weight characteristics and the risk of gestational diabetes. Diabetologia 2010;53:668-78.

10. Ferrara A. Increasing prevalence of gestational diabetes mellitus: A public health perspective. Diabetes Care 2007;30(Suppl. 2):S141-6.

11. March WA, Moore VM, Willson KJ, et al. The prevalence of polycystic ovary syndrome in a community sample under contrasting diagnostic criteria. Hum Reprod 2010;25:544-51.

12. Clark MK, Dillon JS, Sowers M, et al. Weight, fat mass, and central distribution of fat increase when women use depot-medroxyprogesterone acetate for contraception. Int J Obes 2005;29:1252-8.

13. Montague CT, O'Rahilly S. The perils of portliness: Causes and consequences of visceral adiposity. Diabetes 2000;49:883-8.
14. Beksinska ME, Smit JA, Kleinschmidt I, et al. Prospective study of weight change in new adolescent users of DMPA, NET-EN, COCs, nonusers and discontinuers of hormonal contraception. Contraception 2010;81:30-4.

15. Xiang AH, Kawakubo M, Buchanan TA, et al. A longitudinal study of lipids and blood pressure in relation to method of contraception in Latino women with prior gestational diabetes mellitus. Diabetes Care 2007;30: 1952-8.

16. Westhoff C, Jain JK, Milsom I, et al. Changes in weight with depot medroxyprogesterone acetate subcutaneous injection $104 \mathrm{mg} / 0.65 \mathrm{~mL}$. Contraception 2007;75: 261-7.

17. Brache V, Faundes A, Alvarez F, et al. Nonmenstrual adverse events during use of implantable contraceptives for women: data from clinical trials. Contraception 2002;65:63-74.

18. Korver T, Dieben T, Vree M, et al. A double-blind study comparing the contraceptive efficacy, acceptability and safety of two progestogen-only pills containing desogestrel $75 \mu \mathrm{g} /$ day and levonorgestrel $30 \mu \mathrm{g} /$ day. Eur J Contracept Reprod Health Care 1998;3: 169-78.

19. Gallo MF, Lopez LM, Grimes DA, et al. Combination contraceptives: Effects on weight. Cochrane Database Syst Rev 2008;CD003987.

20. Milsom I, Lete I, Bjertnaes A, et al. Effects on cycle control and bodyweight of the combined contraceptive ring, Nuvaring, versus an oral contraceptive containing $30 \mu \mathrm{g}$ ethinyl estradiol and $3 \mathrm{mg}$ drospirenone. Hum Reprod 2006;21:2304-11.

21. Piccoli A, Crosignani PG, Nappi C, et al. Effect of the ethinylestradiol/norelgestromin contraceptive patch on body composition. Results of bioelectrical impedance analysis in a population of Italian women. Nutr J 2008;7:21.

22. Morin-Papunen LC, Vauhkonen I, Koivunen RM, et al. Endocrine and metabolic effects of metformin versus ethinyl estradiol-cyproterone acetate in obese women with polycystic ovary syndrome: A randomized study. J Clin Endocrinol Metab 2000;85:3161-8.

23. Meyer C, McGrath BP, Teede HJ. Effects of medical therapy on insulin resistance and the cardiovascular system in polycystic ovary syndrome. Diabetes Care 2007;30:471-8.

24. Luque-Ramirez M, Álvarez-Blasco F, Botella-Carretero $\mathrm{JI}$, et al. Comparison of ethinyl-estradiol plus cyproterone acetate versus metformin effects on classic metabolic cardiovascular risk factors in women with the polycystic ovary syndrome. J Clin Endocrinol Metab 2007;92: 2453-61. 
25. Hoeger K, Davidson K, Kochman L, et al. The impact of metformin, oral contraceptives, and lifestyle modification on polycystic ovary syndrome in obese adolescent women in two randomized, placebo-controlled clinical trials. J Clin Endocrinol Metab 2008;93:4299-306.

26. Edelman AB, Carlson NE, Cherala $G$, et al. Impact of obesity on oral contraceptive pharmacokinetics and hypothalamic-pituitary-ovarian activity. Contraception 2009;80:119-27.

27. Weisberg E, Fraser IS, Lacarra M, et al. Efficacy, bleeding patterns, and side effects of a 1-year contraceptive vaginal ring. Contraception 1999;59:311-8.

28. Trussell J, Schwarz EB, Guthrie KA. Obesity and oral contraceptive failure. Contraception 2009;79:334-8.

29. Smallwood GH, Meador ML, Lenihan JP, et al. Efficacy and safety of a transdermal contraceptive system. Obstet Gynecol 2001;98:799-805.

30. Klipping C, Duijkers I, Trummer D, et al. Suppression of ovarian activity with a drospirenone-containing oral contraceptive in a 24/4 regimen. Contraception 2008; 78:16-25.

31. Trussell J, Guthrie KA, Schwarz EB. Much ado about little: Obesity, combined hormonal contraceptive use and venous thrombosis. Contraception 2008;77:143-6.

32. Kahn HS, Curtis KM, Marchbanks PA. Effects of injectable or implantable progestin-only contraceptives on insulin-glucose metabolism and diabetes risk. Diabetes Care 2003;26:216-25.

33. Hedderson MM, Ferrara A, Williams MA, et al. Androgenicity of progestins in hormonal contraceptives and the risk of gestational diabetes mellitus. Diabetes Care 2007;30:1062-8.

34. Tabák AG, Jokela M, Akbaraly TN, et al. Trajectories of glycaemia, insulin sensitivity, and insulin secretion before diagnosis of type 2 diabetes: An analysis from the Whitehall II study. Lancet 2009;373:2215-21.

35. Spellacy WN, Buhi WC, Birk SA. The effect of estrogens on carbohydrate metabolism: Glucose, insulin, and growth hormone studies on one hundred and seventyone women ingesting Premarin, mestranol, and ethinyl estradiol for six months. Am J Obstet Gynecol 1971; 114:378-92.

36. Bonds DE, Lasser N, Qi L, et al. The effect of conjugated equine oestrogen on diabetes incidence: The Women's Health Initiative randomised trial. Diabetologia 2006; 49:459-68.

37. Rochira V, Madeo B, Zirilli L, et al. Oestradiol replacement treatment and glucose homeostasis in two men with congenital aromatase deficiency: Evidence for a role of oestradiol and sex steroids imbalance on insulin sensitivity in men. Diabetic Med 2007;24:1491-5.

38. Muniyappa R, Lee S, Chen H, et al. Current approaches for assessing insulin sensitivity and resistance in vivo:
Advantages, limitations, and appropriate usage. $A m \mathrm{~J}$ Physiol Endocrinol Metab 2008;294:E15-26.

39. Xiang $\mathrm{AH}$, Kawakubo M, Kjos SL, et al. Long-acting injectable progestin contraception and the risk of type 2 diabetes in Latino women with prior gestational diabetes mellitus. Diabetes Care 2006;29:613-7.

40. Nelson AL, Hau Hien Le M, Musherraf Z, et al. Intermediate-term glucose tolerance in women with a history of gestational diabetes: natural history and potential associations with breastfeeding and contraception. Am J Obstet Gynecol 2008;198:699.e1-8.

41. Cagnacci A, Tirelli A, Cannoletta M, et al. Effect on insulin sensitivity of Implanon vs. GnRH agonist in women with endometriosis. Contraception 2005;72: 443-6.

42. Vicente L, Mendonça D, Dingle M, et al. Etonogestrel implant in women with diabetes mellitus. EurJ Contracept Reprod Health Care 2008;13:387-95.

43. Kivelä A, Ruuskanen M, Ågren U, et al. The effects of two progestogen-only pills containing either desogestrel (75 $\mu \mathrm{g} /$ day) or levonorgestrel (30 $\mu \mathrm{g} /$ day) on carbohydrate metabolism and adrenal and thyroid function. Eur J Contracept Reprod Health Care 2001;6:71-7.

44. Rogovskaya S, Rivera R, Grimes DA, et al. Effect of a levonorgestrel intrauterine system on women with type 1 diabetes: a randomized trial. Obstet Gynecol 2005;105: $811-5$.

45. Cagnacci A, Ferrari S, Tirelli A, et al. Insulin sensitivity and lipid metabolism with oral contraceptives containing chlormadinone acetate or desogestrel: A randomized trial. Contraception 2009;79:111-6.

46. Elkind-Hirsch KE, Darensbourg C, Ogden B, et al. Contraceptive vaginal ring use for women has less adverse metabolic effects than an oral contraceptive. Contraception 2007;76:348-56.

47. Cagnacci A, Ferrari S, Tirelli, et al. Route of administration of contraceptives containing desogestrel/etonogestrel and insulin sensitivity: A prospective randomized study. Contraception 2009;80:34-9.

48. Lopez LM, Grimes DA, Schulz KF. Steroidal contraceptives: Effect on carbohydrate metabolism in women without diabetes mellitus. Cochrane Database Syst Rev 2009; CD006133.

49. Morin-Papunen L, Vauhkonen I, Koivunen R, et al. Metformin versus ethinyl estradiol-cyproterone acetate in the treatment of nonobese women with polycystic ovary syndrome: A randomized study. J Clin Endocrinol Metab 2003;88:148-56.

50. Cibula D, Fanta M, Vrbikova J, et al. The effect of combination therapy with metformin and combined oral contraceptives (COC) versus COC alone on insulin sensitivity, hyperandrogenaemia, SHBG and lipids in PCOS patients. Hum Reprod 2005;20:180-4. 
51. Cagnacci A, Paoletti AM, Renzi A, et al. Glucose metabolism and insulin resistance in women with polycystic ovary syndrome during therapy with oral contraceptives containing cyproterone acetate or desogestrel. J Clin Endocrinol Metab 2003;88:3621-5.

52. Guido M, Romualdi D, Giuliani M, et al. Drospirenone for the treatment of hirsute women with polycystic ovary syndrome: A clinical, endocrinological, metabolic pilot study. J Clin Endocrinol Metab 2004;89:2817-23.

53. Villaseca P, Hormaza P, Cárdenas I, et al. Ethinylestradiol/cyproterone acetate in polycystic ovary syndrome: Lipid and carbohydrate changes. Eur J Contracept Reprod Health Care 2004;9:155-65.

54. Harborne L, Fleming R, Lyall H, et al. Metformin or antiandrogen in the treatment of hirsutism in polycystic ovary syndrome. J Clin Endocrinol Metab 2003;88:411623.

55. Lemay A, Dodin S, Turcot L, et al. Rosiglitazone and ethinyl estradiol/cyproterone acetate as single and combined treatment of overweight women with polycystic ovary syndrome and insulin resistance. Hum Reprod 2006;21:121-8.

56. Mastorakos G, Koliopoulos C, Deligeoroglou E, et al. Effects of two forms of combined oral contraceptives on carbohydrate metabolism in adolescents with polycystic ovary syndrome. Fertil Steril 2006;85:420-7.

57. Banaszewska B, Pawelczyk L, Spaczynski RZ, et al. Effects of simvastatin and oral contraceptive agent on polycystic ovary syndrome: Prospective, randomized, crossover trial. J Clin Endocrinol Metab 2007;92:456-61.

58. Åkerlund $\mathrm{M}$, Almström $\mathrm{E}$, Högstedt $\mathrm{S}$, et al. Oral contraceptive tablets containing 20 and $30 \mu \mathrm{g}$ of ethinyl estradiol with $150 \mu \mathrm{g}$ desogestrel. Their influence on lipids, lipoproteins, sex hormone binding globulin and testosterone. Acta Obstet Gynecol Scand 1994;73:136-43.

59. Skouby SO, Endrikat J, Düsterberg B, et al. A 1-year randomized study to evaluate the effects of a dose reduction in oral contraceptives on lipids and carbohydrate metabolism: $20 \mu \mathrm{g}$ ethinyl estradiol combined with $100 \mu \mathrm{g}$ levonorgestrel. Contraception 2005;71:111-7.

60. Klipping C, Marr J. Effects of two combined oral contraceptives containing ethinyl estradiol $20 \mu \mathrm{g}$ combined with either drospirenone or desogestrel on lipids, hemostatic parameters and carbohydrate metabolism. Contraception 2005;71:409-16.

61. Creasy GW, Fisher AC, Hall N, et al. Transdermal contraceptive patch delivering norelgestromin and ethinyl estradiol: Effects on the lipid profile. J Reprod Med 2003;48:179-86.

62. Tuppurainen M, Klimscheffskij R, Venhola M, et al. The combined contraceptive vaginal ring (Nuvaring ${ }^{\circledR}$ ) and lipid metabolism: a comparative study. Contraception 2004;69:389-94.
63. Rautio K, Tapanainen JS, Ruokonen A, et al. Effects of metformin and ethinyl estradiol-cyproterone acetate on lipid levels in obese and non-obese women with polycystic ovary syndrome. Eur J Endocrinol 2005;152: 269-75.

64. Skouby SO, Kühl C, Mølsted-Pedersen L, et al. Triphasic oral contraception: metabolic effects in normal women and those with previous gestational diabetes. Am J Obstet Gynecol 1985;153:495-500.

65. Kjos SL, Shoupe D, Douyan S, et al. Effect of low-dose oral contraceptives on carbohydrate and lipid metabolism in women with recent gestational diabetes: Results of a controlled, randomized, prospective study. Am J Obstet Gynecol 1990;163:1822-7.

66. Kayikcioglu F, Gunes M, Ozdegirmenci O, et al. Effects of levonorgestrel-releasing intrauterine system on glucose and lipid metabolism: A 1-year follow-up study. Contraception 2006;73:528-31.

67. Biswas A, Viegas OAC, Roy AC. Effect of Implanon ${ }^{\circledR}$ and Norplant ${ }^{\mathbb{R}}$ subdermal contraceptive implants on serum lipids - a randomized comparative study. Contraception 2003;68:189-93.

68. Merki-Feld GS, Imthurn B, Seifert B. Effects of the progestagen-only contraceptive implant Implanon ${ }^{\circledR}$ on cardiovascular risk factors. Clin Endocrinol 2008;68:35560.

69. Barkfeldt J, Virkkunen A, Dieben T. The effects of two progestogen-only pills containing either desogestrel (75 $\mu \mathrm{g} /$ day) or levonorgestrel (30 $\mu \mathrm{g} /$ day) on lipid metabolism. Contraception 2001;64:295-9.

70. Chasan-Taber L, Willett WC, Manson JE, et al. Prospective study of oral contraceptives and hypertension among women in the United States. Circulation 1996;94:483-9.

71. Curtis KM, Mohllajee AP, Martins SL, et al. Combined oral contraceptive use among women with hypertension: A systematic review. Contraception 2006;73:179-88.

72. Sica DA. Drospirenone: An antihypertensive in waiting. Hypertension 2006;48:205-6.

73. Oelkers W, Foidart JM, Dombrovicz N, et al. Effects of a new oral contraceptive containing an antimineralocorticoid progestogen, drospirenone, on the reninaldosterone system, body weight, glucose tolerance, and lipid metabolism. J Clin Endocrinol Metab 1995;80: 1816-21.

74. Gaffield ME, Curtis KM, Mohllajee AP, et al. Medical eligibility criteria for new contraceptive methods: Combined hormonal patch, combined hormonal ring and the etonogestrel implant. Contraception 2006;73:13444.

75. Funk S, Miller MM, Mishell DR, et al. Safety and efficacy of Implanon ${ }^{\mathrm{TM}}$, a single-rod implantable contraceptive containing etonogestrel. Contraception 2005;71:319-26. 